\title{
Nosocomial Infections in a Morocco Burn Unit
}

\author{
Amine Rafik*, Hakim Chabbak, Kawtare Jouhri, Mounia Diouri, Naima Bahechar, \\ Abdessamad Chlihi \\ National Center for Burns and Plastic Surgery, Casablanca, Morocco \\ Email: ${ }^{*}$ Aminerafik8@gmail.com
}

Received 11 March 2015; accepted 26 March 2015; published 1 April 2015

Copyright (C) 2015 by authors and OALib.

This work is licensed under the Creative Commons Attribution International License (CC BY). http://creativecommons.org/licenses/by/4.0/

(c) (i) Open Access

\begin{abstract}
Introduction: The bacterial nosocomial infection remains a common cause of death in patients who have sustained a severe burn injury. Material and Methods: We conducted a prospective study of 45 patients hospitalized in the ICU burns Hospital IBN-ROCHD of Casablanca over a period of six months, from 1 January 2014 to 30 June 2014. The criteria for nosocomial infection were those of the Center for Disease Control in Atlanta in 1988. Result: Incidence rates were calculated. The bacterial ecology of the service was described as also antibiotype. The population was predominantly male (14 women and 31 men). Their average age was 39 years; the occurrence of 17 nosocomial infections in 45 patients appeared from this study. The cumulative incidence was 103 infections per 1000 days of treatment. Regarding the characteristics of bacterial infections, infected sites were skin (69\%), blood (18\%), urinary tract $(12 \%)$ and lungs $(1 \%)$. The main organisms were: Staphylococcus sp. (37.7\%), Pseudomonas aeruginosa (19.8\%), Enterococcus faecalis and Proteus mirabilis (18.5\%). Staphylococci were méthicillin-resistant in $22 \%$ of cases. Pseudomonas and Acinetobacter were multi-resistant (66\%). The establishment of the bacterial ecology of the service helped us set the right rules of prescription of antibiotics. Conclusion: Finally, controlling the epidemic risk posed by the emergence of resistant organisms is necessary to combine the practice of good antibiotic therapy and prevention.
\end{abstract}

\section{Keywords}

Nosocomial Infection, Burn, Epidemiology, Bacteriology

Subject Areas: Dermatology

\section{Introduction}

Even though the progress in management of the burnt patients has allowed the survival of seriously affected pa-

"Corresponding author.

How to cite this paper: Rafik, A., Chabbak, H., Jouhri, K., Diouri, M., Bahechar, N. and Chlihi, A. (2015) Nosocomial Infections in a Morocco Burn Unit. Open Access Library Journal, 2: e1394. http://dx.doi.org/10.4236/oalib.1101394 
tients, the bacterial nosocomial infection remains one of the principal causes of morbidity and mortality of the burnt patient. As we know, there are no published data about the nosocomial infections of burn in Morocco. This paper will present the epidemiology and results of 21 patients admitted with chemical burn to this hospital over the period of 2009-2014.

The aim of this survey is to establish the infection incidence in our unit as well as to study the sensitivity of the isolated germs to different antibiotics.

\section{Material and Methods}

This survey was carried out in the intensive care department of the burnt patients in IBN ROCHD university hospital center in Casablanca over a 6 month period, from the first of January 2014 to the 30th of June 2014. We studied the nosocomial infections among patients directly admitted in intensive care unit and stayed in hospital more than 48 hours in this unit. The criteria of nosocomial infections retained were those of the CDC (centers for disease control and prevention) of Atlanta in 1988, modified in 1992. Due to the particularities specific to the patients burnt according to the infection clinical signs, general and local, these criteria were case-based adapted upon the department clinician's decision. At admission of each patient, systematic samplings were performed in search of an actual colonization or a real infection. We carried out a series of 3 hemocultures, urine cytobacterogical exam, protected distal bronchic sampling if the patient had been intubated before. Each sampling was bacteriologically analysed. The data were analysed using SPSSv16 software.

\section{Results}

The population was mainly masculine (14 women and 31 men). Their mean age was 39 years \pm 23 ; there were 7 patients whose age $\leq 16$ years. That is $15.5 \%$ of the population. For the patients whose age was over 16 years the mean body mass index (BMI) was $22.1 \mathrm{KG} / \mathrm{m}^{2}$. We found that 18 patients had associated defects (Table 1).

The burnt body surface (BBS) was $33.2 \% \pm 6.1 \%$. The mean value of the standard burning unit (U.B.S.) was $48.9 \pm 29.1$. The mean ABSI (abbreviated burn severity index) was $60 \pm 5.2$. Among the mechanisms of the burns, we detected 43 patients (95.5\%) with thermal burns of whom 36 (83.7\%) with burns by flames and 7 (16.2\%) by contact; two patients (4.4\%) showed electric burns. As for the burn localization, it involved the face in 3 patients (6.6\%) and the perinea in 21 patients (46.6\%). Seven patients (15.5\%) showed inhalation lesions of whom two were affirmed and five (72\%) strongly suspected. Two patients (4.4\%) had associated traumatic lesions that were diverse fractures or skull traumatism. We detected 23 patients (55\%) had been operated, that is to say 2.4 interventions per patient \pm 1 .6. The mean delay of the first intervention according to the date of the burn was 18.2 days \pm 9.2 . Eleven patients (27\%) had discharge incisions with an average of 4.2 discharge incision per patient \pm 2.7 . Thirty eight patients (85\%) had baths with an average of 12.9 baths per patient \pm 23.8 . The duration of the mean sojourn in intensive care 42.9 days \pm 37 ; that is 1935 days of intensive care in all. As for the duration of exposure to the invasive devices, it is summarized in Table 2.

Nosocomial infections are detected in 17 patients that is $37 \%$ of population. So there is a rate of 3.7 nosocomial infections. The instantaneous incidence of the nosocomial infections was 20 nosocomial infections per 1000 days of admission to hospital. The distribution of the nosocomial infection with respect to the sites is summed up in Figure 1.

The first infection of blood occurred in average 6.9 days after admission. The first pulmonary infection occurred 10.5 days after admission and the first skin infection after 11.5 days after admission. The mean delay of

Table 1. Distribution of the associated defects in our patients $(n=18)$.

\begin{tabular}{ccc}
\hline Medical records & Number (n= 18) & Rate (\%) \\
Epilepsy & 7 & 15.5 \\
Diabetes & 4 & 6.9 \\
Tobacco & 3 & 4.5 \\
Alcohol & 2 & 4.4 \\
Heart disease & 2 & 4.4 \\
\hline
\end{tabular}


Table 2. Data of exposure to invasive devices $(n=45)$.

\begin{tabular}{cccc}
\hline & \multicolumn{2}{c}{ Patient } & \multicolumn{2}{c}{$\begin{array}{c}\text { Average duration per day } \\
\text { (J) }\end{array}$} \\
\cline { 2 - 4 } Artificial ventilation & Number & $\mathbf{( \% )}$ & $37.1 \pm 6.2$ \\
Urinary catheter & $9 / 45$ & 20 & $24.7 \pm 7.5$ \\
Central venous catheterization & $11 / 45$ & 24.4 & $21.3 \pm 7.9$ \\
\hline
\end{tabular}

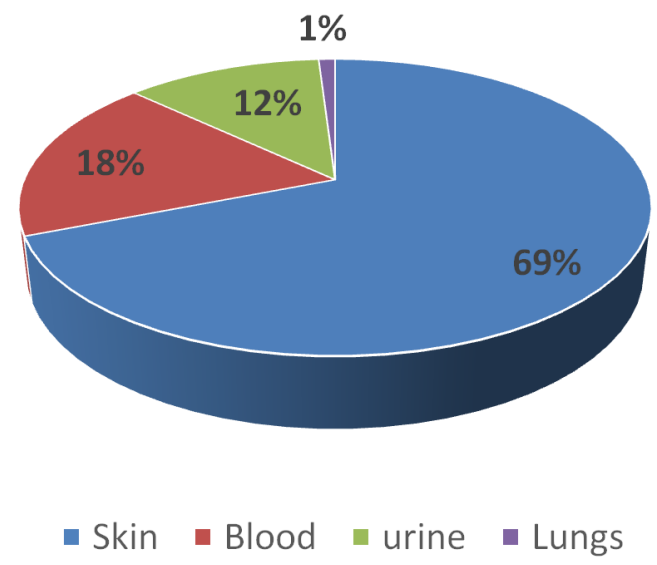

Figure 1. Distribution of nosocomial infection sites.

the first urinary infection was 18.1 days after admission. The incidence of different germs detected in the samplings is reported on the Table 3.

Concerning the resistance of the germs to the different antibiotics, we noticed the presence of Staphylococcus aureus resisting to meticillins (MRSA) in 22\% of the cases as well as multiresistant Pseudomonas aeruginosa in $66 \%$ of the cases (Ceftazidim, aminosides or fluoroquinolones). However, it remains sensitive to Imipenem. Enterobacteria (K. pneumonia, Enterobacter, Proteus mirabilis) show in $20 \%$ of the cases a resistance to beta-lactamins (except imipeneme), to fluoroquinolones, and to aminosides. Acinetobacter baumanni is multiresistant but remains sensitive to imipeneme. No case was revealed in our series concerning Enterococcus resistant to vancomycin.

\section{Discussion}

The incidence of nosocomial infections in intensive care is 3 to 4 times more important than that of the units other than intensive care [1] [2]. It should be noted that our incidence density of 20 nosocomial infections per 1000 days of hospitalization is approximately equivalent to the one found in literature; 23 nosocomial infections per 1000 days of hospitalization in Garner et al. [3]. In our work and that of Chaibdraa [4] the cutaneous site is more frequent: it represents $69 \%$ of nosocomial infections. It is the least frequent in Wurtz's study [5]. These results come closer relatively to those carried out by Cremer's works [6] and Taylor's [7] where skin infections are the most frequently encountered with higher incidences compared to other studies. Despite the ineluctable character of contamination of the brunt skin and its high risk of infection, we obtained relatively high incidences, occurrences, accounted for by our local management (Flammazine ${ }^{\circledR}$ ), which is identical to the one of Cremer's team [6], and different from the one of Taylor's team [7] who called for balneotherapy only after cutaneous covering. The weak incidence of the skin infections found by Wurtz [5] (3\% of nosocomial infections) is due to the common practice of precocious excision graft. It was not the case in our study; we called for secondary healing while waiting for the skin covering. As for the frequency, the blood site comes second after the skin site and before the urinary and pulmonary sites with incidences close to those reported in literature. In fact, our findings are comparable with and similar to those of Weber's team [8]; $15 \%$ of the nosocomial infections. The incidence of urinary infections in our study is certainly due to, on one hand, the proportion of the patients with urinary catheter (45\%) and on the other hand, to the long period of urinary catheterization; 26 days in average 
Table 3. Incidence of the nosocomial infection by germs $(n=45)$.

\begin{tabular}{|c|c|c|}
\hline Germe & Number & $\%$ \\
\hline Staphylococci ssp & 17 & 37.7 \\
\hline Pseudomonas aeruginosa & 9 & 19.8 \\
\hline Proteus mirabilis & 6 & 13.2 \\
\hline Acinetobacter baumannii & 5 & 11.1 \\
\hline Enterococcus. faecalis & 3 & 6.5 \\
\hline Klebsiella pneumoniae & 2 & 4.4 \\
\hline Enterobacter cloacae & 1 & 2.2 \\
\hline Streptococci ssp & 1 & 2.2 \\
\hline Escherichia coli & 1 & 2.2 \\
\hline
\end{tabular}

versus 20 days in the study of Cremer's team [6]. Taylor's and Cremer's studies found incidences higher to ours but these authors did not precise the duration of urinary catheterization. Wurts [5] found a density superior to ours as well as higher proportion of urinary infections among the nosocomial infections (36\%). In our study, 58\% of the patients are holders of urinary catheter; which accounted for this high incidence but it does not give any information on the duration of the investigation. In the pulmonary site, in our study, we detected one nosocomial pneumopathy nosocomial to Acinetobacter baumanii. Inhalations of smokes are very rare in our patients. Nosocomial pneumopathies are, in general, a major cause of mortality and of morbidity in the burnt patients [9] [10]. They are highly linked to the initial severity of the burning and mostly supervene in burnt patients presenting lesions of inhalation and in those who underwent mechanical ventilation. According to the works of Miguel A. [11], pneumopathies are two times more frequent in group of patients with inhalation lesions more than in a group without inhalation lesions.

The existence of an eight-day delay (the usual golden days) from the burning to the infection was already evoked in 1993 [12] [13]. Our study found an identical delay for the supervention of the first nosocomial infection and the first nosocomial infections, site by site, as in Cremer's study [6]. The mean delay, very short [13] days, between the first nosocomial infection and the second witnesses that there is a context of multi-infections more than precocious recurrences.

Our study is marked by a predominance of staphylococcus with $37.6 \%$ of the nosocomial infections, of whom 59\% are Staphylococcus aureus. Far behind, we detected the Pseudomonas aeruginosa with $19.8 \%$.

Of according to literature data, we distinguish two groups of studies: those such as we did, who detected a majority of Staphylococus and the others who found a predominance of pyocianic bacillus. Hydrotherapy is a risk to infect the non infected burnt zones. Cremer's team [6], also found that a majority of Pseudomonas aeruginosas using precocious balneotherapy. The reduction of the burnt patient's baths by the use of bandage in bed discards this emergency and we launch this procedure in our department. The second reason of the pyocianic emergency, in our study, would be the increased use systemically of antibiotics.

\section{Conclusion}

Due to the severity of the infection and main cause of mortality in the large burn, all the means are put to use and oriented to bring about prevention measures. To obtain the best possible outcomes, it is important to make use of the wealth of experience and research published in the bacterial nosocomial infection in critical care while also striving to produce further high-quality research specific to burnt patients.

\section{Conflict of Interest}

No conflict.

\section{References}

[1] Egozi, D., Hussein, K., Filson, S., Mashiach, T., Ullmann, Y. and Raz-Pasteur, A. (2014) Bloodstream Infection as a Predictor for Mortality in Severe Burn Patients: An 11-Year Study. Epidemiology and Infection, 142, 2172-2179. http://dx.doi.org/10.1017/S0950268813002501 
[2] Guidry, C.A., Mansfield, S.A., Sawyer, R.G. and Cook, C.H. (2014) Resistant Pathogens, Fungi, and Viruses. The Surgical Clinics of North America, 94, 1195-1218. http://dx.doi.org/10.1016/j.suc.2014.08.010

[3] Garner, J.S., Jarvis, W.R., Emori, T.G., Horan, T.C. and Hughes, J.M. (1988) CDC Definitions for Nosocomial Infections, 1988. American Journal of Infection Control, 16, 128-140. http://dx.doi.org/10.1016/0196-6553(88)90053-3

[4] Chandrasekar, P.H., Kruse, J.A. and Mathews, M.F. (1986) Nosocomial Infection among Patients in Different Types of Intensive Care Units at a City Hospital. Critical Care Medicine, 14, 508-510. http://dx.doi.org/10.1097/00003246-198605000-00017

[5] Wurtz, R., Karajovic, M., Dacumos, E., Jovanovic, B. and Hanumadass, M. (1995) Nosocomial Infections in a Burn Intensive Care Unit. Burns, 21, 181-184. http://dx.doi.org/10.1016/0305-4179(95)80005-9

[6] Cremer, R., Ainaud, P., Le Bever, H., Fabre, M. and Carsin, H. (1996) Infections nosocomiales dans un service de brûlés. Résultats d'une enquête prospective d'un an. Annales Françaises d'Anesthésie et de Réanimation, 15, 599-607. http://dx.doi.org/10.1016/0750-7658(96)82125-3

[7] Taylor, G.D., Kibsey, P. and Kirkland, T. (1992) Predominance of Staphylococcal Organisms in Infections Occurring in a Burns Intensive Care Unit. Burns, 18, 332-335. http://dx.doi.org/10.1016/0305-4179(92)90158-Q

[8] Weber, J.M., Sheridan, L., Pasternack, S. and Tompkins, G. (1997) Nosocomial Infections in Pediatric Patients with Burns. American Journal of Infection Control, 25, 195-201. http://dx.doi.org/10.1016/S0196-6553(97)90004-3

[9] Wenzel, R.P., Thompson, R.L. and Landry, S.M. (1983) Hospital-Acquired Infections in Intensive Care Unit Patients: An Overview with Emphasis on Epidemics. Infection Control, 4, 371-375.

[10] Mayes, T., Gottschlich, M.M., James, L.E., Allgeier, C., Weitz, J. and Kagan, R.J. (2015) Clinical Safety and Efficacy of Probiotic Administration Following Burn Injury. Journal of Burn Care \& Research: Official Publication of the American Burn Association, 36, 92-99. http://dx.doi.org/10.1097/BCR.0000000000000139

[11] de la Cal, M.A., Cerda, E., Garcia-Hierro, P. and Lorente, L. (2001) Pneumonia in Patients with Burns. Chest, 119, 1160-1165. http://dx.doi.org/10.1378/chest.119.4.1160

[12] Fournier, P.E. and Richet, H. (2006) The Epidemiology and of Control of Acinetobacter baumannii in Health Care Facilities. Clinical Infectious Diseases, 42, 692-699. http://dx.doi.org/10.1086/500202

[13] Agnihotri, N., Gupta, V. and Joshi, R.M. (2004) Aerobic Bacterial Isolates from Burn Wound Infections and Their Antibiograms-A Five-Year Study. Burns, 30, 2413. http://dx.doi.org/10.1016/j.burns.2003.11.010 